\title{
Pulsed Power System for the Orion High Power Laser
}

\author{
M.J. Mead ${ }^{a, *}$, S. Moncho-Banuls ${ }^{b}$, S. PottieR $^{b}$ And J.P. Brasile ${ }^{b}$ \\ ${ }^{a}$ AWE, Aldermaston, Reading, Berksire, RG7 4PR, UK \\ ${ }^{b}$ Thales Communications, 160 Boulevard de Valmy, 92704, France
}

\begin{abstract}
This paper describes the design and testing of the pulsed power system for the Orion Laser, which will be used for high temperature and density plasma physics research. The system supplies 8 MJ of energy to laser amplifiers and Faraday rotators. It consists of 17 capacitor bank modules, each with up to sixteen $150 \mu \mathrm{F}$ charge storage capacitors, $25 \mathrm{kV}$ power supply and controls. The energy is delivered by spark-gap switches to give a pre-pulse to ionise the flashlamps and a main pulse of $490 \mu \mathrm{s}$. The system delivers 5 shots a day with less than $0.2 \%$ variation in charge voltage.
\end{abstract}

PACS numbers: 42.60.By, 84.60.Ve

\section{Orion laser}

The Orion laser is being built at Atomic Weapons Establishment (AWE) for plasma physics experiments up to 10 million deg $\mathrm{C}$ and 3 times solid density [1]. It has twelve beams each delivering $500 \mathrm{~J}$ to a microscopic target. Ten are long pulse beams of 0.1 to $5 \mathrm{~ns}$ and two are Petawatt $\left(10^{15} \mathrm{~W}\right)$ beams of 0.5 to $20 \mathrm{ps}$. The laser has a pulse power system (PPS) to supply the large aperture (100 to $200 \mathrm{~mm}$ diameter) final sections with energy to pump neodymium glass amplifiers and current to drive Faraday rotators. The long pulse beams pass 4 times through four $200 \mathrm{~mm}$ amplifiers. The Petawatt beams pass twice through a $100 \mathrm{~mm}$ rotator and amplifier, once through a $150 \mathrm{~mm}$ amplifier and rotator, and once through three $200 \mathrm{~mm}$ amplifiers. The small signal gain (SSG) per single amplifier pass is $2.2,3.5$ and 10 for the $200 \mathrm{~mm}, 150 \mathrm{~mm}$ and $100 \mathrm{~mm}$ amplifiers, respectively. Each amplifier has 8 Xenon filled flashlamps of $1.2 \mathrm{~m}$ by $25 \mathrm{~mm}$ diameter arranged in series pairs. The pump energy required is about $160 \mathrm{~kJ}$ per amplifier. Multi-pass amplifier configurations are efficient but require a very stable PPS with fine adjustment. For $N$ passes through $M$ amplifiers of power gain $G$ it can be shown that to achieve a balance between laser beams of $B$ the PPS voltage stability must be better than $B /(2 N M \ln G)$. Hence for the long pulse beams the PPS stability must be better than $0.2 \%$ to achieve the required $5 \%$ beam balance.

\section{Pulsed power system}

The PPS consists of 17 capacitor bank modules (CBMs) organised as shown in Table to supply the 12 beams and a test laboratory for measuring amplifier SSG.

Each CBM is an autonomous unit containing up to 16 main charge storage capacitors, a $25 \mathrm{kV}$ charging power

\footnotetext{
* corresponding author; e-mail: jenny.mead@dsl.pipex.com
}

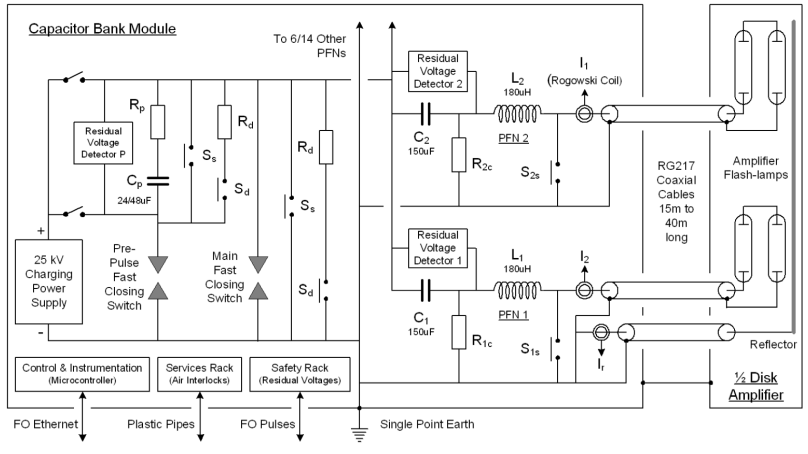

Fig. 1. Scheme showing main components of amplifier CBM.

supply, fast closing switches, safety circuits, instrumentation and controls. The design of the CBMs for amplifiers shown in Fig. 1 is more interesting than for rotators. A pre-pulse of $900 \mathrm{~J}$ is generated to ionise the flashlamps before the main pulse which allows the main pulse energy to be set over a wide range. This is also expected to improve efficiency, stability and flashlamp life. The main charge is held in $150 \mu \mathrm{F}$ metal film capacitors $\left(C_{1}\right.$, $\left.C_{2}, \ldots\right)$ which are charged in $55 \mathrm{~s}$ to the required voltage $V_{m}$. The pre-pulse is generated by firing a pre-pulse switch which discharges some of the main charge into the pre-pulse capacitor $C_{p}$. This is charged to a voltage $V_{p}=25000-V_{m}$ to keep the pre-pulse energy constant.

\section{CBM design and component tests}

The CBMs were designed to minimise electromagnetic interference. The power supplies and control electronics are well shielded at the bottom of the CBM. Internal and external connections are made by fibre optic (FO) cables or plastic air pipes wherever possible. The power supplies to pulsed circuits are disconnected prior to firing a pulse. There is a single earth point for each CBM and the amplifiers or rotators connected to it. The current flow 
through alternate pulse forming inductors is reversed to minimise the external magnetic field. EMC tests were performed during the design to ensure there was no interference between the pre and main pulses or between adjacent CBMs.

\section{TABLE}

List of CBM types.

\begin{tabular}{|c|c|c|c|c|}
\hline \multirow[t]{2}{*}{ Type } & \multirow{2}{*}{$\begin{array}{c}\text { Load supplied } \\
\text { by one CBM }\end{array}$} & \multicolumn{3}{|c|}{ Number required for beams or Lab. } \\
\hline & & Long pulse & Petawatt & SSG Lab \\
\hline 200 & $\begin{array}{l}4 \text { or } 3 \times 200 \mathrm{~mm} \\
\text { aperture } \quad \text { disk } \\
\text { amps. }\end{array}$ & 10 & 2 & \\
\hline $150 / 100$ & $\begin{array}{l}150 \quad \mathrm{~mm} \text { disk } \\
\text { amp. }+100 \mathrm{~mm} \\
\text { disk amp. }\end{array}$ & & 2 & \\
\hline 150FAR & $\begin{array}{lr}2 \times 150 & \mathrm{~mm} \\
\text { Faraday } & \text { rota- } \\
\text { tors } & \end{array}$ & & 1 & \\
\hline 100FAR & $\begin{array}{ll}2 \times 100 & \mathrm{~mm} \\
\text { Faraday } & \text { rota- } \\
\text { tors } & \end{array}$ & & 1 & \\
\hline SSG & $\begin{array}{l}\text { Any one of } \\
\text { above }\end{array}$ & & & 1 \\
\hline
\end{tabular}

Personnel safety is ensured by independent hardwired systems. The Orion safety interlock system provides two air signals to the CBM to enable the opening of the dumps switches $\left(S_{d}\right)$ and shorting switches $\left(S_{s}, S_{1 s}, S_{2 s}\right)$ by the controls prior to charging. There is also a residual voltage detection system which gives an indication to personnel outside the PPS room of the charge status. This is derived from passive detectors fitted to every charge storage capacitor which generate a flashing FO signal when the voltage is above $100 \mathrm{~V}$. The indication outside is latched red when one or more capacitors are charged and yellow when all are charged for testing the integrity of the system. The CBM layout is also made so all the pulse power and safety components can be inspected at a safe distance in front of the CBM.

The pulse currents are measured using Rogowski coils and the waveforms stored for post-shot fault diagnosis such as identifying broken flashlamps [2]. The latter is an expected event which the CBMs are designed to withstand. The worst case broken flashlamp has been modelled as a short-circuit fault to confirm that the integral $i^{2} t$ and voltage reversal does not damage critical components. The possibility of a direct short circuit of a charged capacitor has also been considered. The selected capacitor type has been shorted circuit tested by the French Atomic Energy Commission (CEA) for Laser Megajoule (LMJ) [3].

The requirement for high reliability led to extensive testing of critical components early in the design. A pre-production CBM was fitted with a set of $1 \mu \mathrm{F} 40 \mathrm{kV}$ capacitors made in the same cases as the $150 \mu \mathrm{F} 25 \mathrm{kV}$ capacitors. This was used to verify the insulation to $40 \mathrm{kV}$ during both charging and discharge of the CBM. The fast closing switches were also tested early because a very high charge transfer is required with no "pre-fires" or "miss- -fires". The no pre-fire requirement is achieved by setting the self-breakdown voltage to $40 \mathrm{kV}$ and the no miss-fire requirement is achieved by setting the triggering voltage to over $100 \mathrm{kV}$. The switch has for reliability only two graphite electrodes (i.e. no trigger electrode). It has been used in other applications at $400 \mathrm{kA}$ but for Orion the nominal current is set at $80 \mathrm{kA}$ for long life. The CBM type 200 has two switches for the main pulse and one for the pre-pulse. The trigger is provided by a $120 \mathrm{kV}$ solid-state Marx generator.

\section{CBM performance}

The performance of the CBMs was modelled using PSpice during design using the Markiewicz flashlamp model [4] and is close to the performance measured during factory tests as shown in Fig. 2. These show efficient

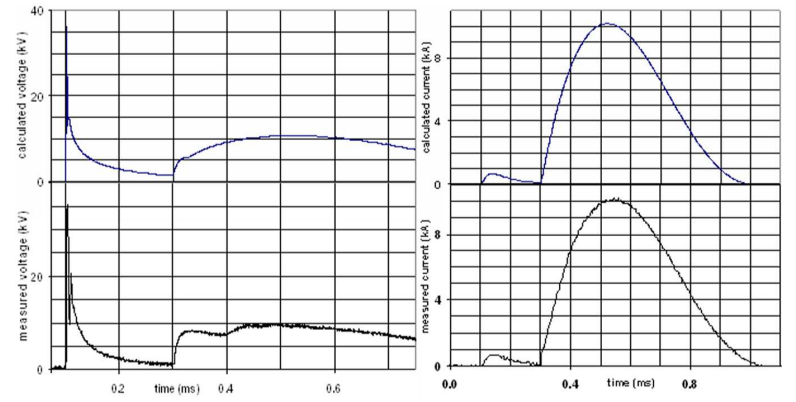

Fig. 2. Performance of amplifier $\mathrm{CBM}$ at $24 \mathrm{kV}$ by modelling at the top and measurement at the bottom showing the flashlamp voltage $(\mathrm{kV})$ on the left and current $(\mathrm{kA})$ on the right plotted against time $(\mathrm{ms})$ with the pre-pulse triggered at $0.1 \mathrm{~ms}$ and main pulse at $0.3 \mathrm{~ms}$.

performance with no transient over voltage at the start of the main pulse showing the flashlamp pairs are fully ionised by the $900 \mathrm{~J}$ pre-pulse. The timing jitter and charge voltage stability measured over 30 pulses were $1 \mu \mathrm{s}$ and $0.1 \%$ which meets the required specification.

A pre-production CBM is being subjected to an 8000 shot accelerated life test and the production CBMs are being manufactured at the Thales GERAC facility adjacent to LMJ near Bordeaux.

\section{References}

[1] C. Edwards, Project Orion, Modernising Defence - Defence Management Journal, Issue 34, www. defencemanagement. com/journal. asp.

[2] D.A. Pepler, P. Holligan, C.J. Reason, W.J. Lester, R.W.W. Wyatt, CLRC Rutherford Appleton Laboratory, Central Laser Facility Annual Report 01 (2000).

[3] P. Michalczyk, C. Friel, C. Vincent, J.P. Marret, J.M. Mexmain, D. Rubin de Cervens, P. Pere, Proceedings of 14th IEEE International Pulse Power Conference, 2003.

[4] R.G. Hohlfeld, W. Manning, D.A. MacLennan, Applied Optics 22, 13 (1983). 